cuts for science-and-technology research programmes at $4 \%$ relative to 2010 . A Republican demand to strip the agency of its authority to regulate greenhouse-gas emissions was also removed from the final agreement. "On climate, it is a pretty strong victory for the administration," says David Goldston, director of government affairs at the Natural Resources Defense Council in Washington DC. Although the administration gave some ground, Goldston says, the bill no longer represents an outright assault on environmental policies. "The broad attack is not there any more," he says. The bulk of the cuts to the EPA - nearly $\$ 1$ billion - have been made in grants to states to develop clean water-related infrastructure. The bill also cuts $\$ 112.5$ million from grants to help state regulatory agencies prepare for new federal air-quality and climate regulations.

\section{ENERGY, EARTH AND SPACE}

The bill passed last week will reduce government funding for research on energy efficiency and renewable energy by $\$ 438$ million, but that's modest compared with the much larger cut proposed by House Republicans. Similarly, the energy department's Advanced Research Project Agency-Energy will receive $\$ 180$ million - far short of Obama's original \$300-million request, but more than triple what the Republicans allocated in February,

At the National Oceanic and Atmospheric Administration (NOAA), the bill prevents money from being spent on the agency's Climate Service, which the administration has proposed as a central clearing house for climate data and longer-term forecasting. It also flatlines funding for weather- and climatemonitoring activities under the Joint Polar Satellite System. On 13 April, NOAA director Jane Lubchenco warned a Senate subcommittee that delays caused by the funding shortfall could jeopardize forecasting ability.

At NASA, a 1.5\% cut will allow the space agency to proceed with plans to develop its human-spaceflight infrastructure, including a multipurpose crew vehicle and a heavylift rocket, to which the new spending bill allocates a minimum of $\$ 1.2$ billion and $\$ 1.8$ billion, respectively. NASA's science programme, which includes the over-budget James Webb Space Telescope (the launch of which has now been delayed until 2018), receives a robust $\$ 5$ billion in the spending bill. But for NASA, as for other science agencies, the new budget leaves longer-term issues unsolved. With the final shuttle flight scheduled for June, the space agency faces a major transition this year - to a hiatus in which the nation is unable to fly its own astronauts. Future budgets will determine the length of that gap.

Additional reporting by Adam Mann and Gwyneth Dickey Zakaib

\title{
Canadian research shift makes waves
}

\section{Agency's focus on industry-driven projects raises concerns that basic science will suffer.}

\section{BY HANNAH HOAG}

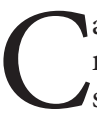
anada's largest research entity has a new focus - and some disaffected scientists. On 1 April, the National Research Council (NRC), made up of more than 20 institutes and programmes with a total annual budget larger than Can $\$ 1$ billion (US\$1 billion), switched to a funding strategy that downplays basic research in favour of programmes designed to attract industry partners and generate revenue. Some researchers suggest that the shift is politically driven, because it brings the agency into philosophical alignment with the governing Conservative Party of Canada, which is in the middle of an election campaign.

The change was announced in a memo from NRC president John McDougall on 2 March, and involves the transfer of authority over $20 \%$ of the agency's research funds and the entire Can\$60-million budget for large equipment and building costs to the NRC's senior executive committee, which will direct it towards research with a focus on economic development, rather than pure science. Until now, individual institutes have had authority over research spending. McDougall wrote that in future, $80 \%$ of the research budget will be centralized, with "curiosity and exploratory activities" to be funded by the remaining $20 \%$.

In Canada, most funding for academic researchers flows through agencies other than the NRC. However, with 4,700 scientists, guest researchers, technologists and support staff pursuing specialities from astrophysics to plant biotechnology at its institutes, the NRC plays a vital part in the nation's scientific community, as a generator of original research and a service provider to government and industry. The shift away from basic science "weakens" the NRC's labs, because they "are required to bridge two cultures - the basic and applied", says John Polanyi, a Nobel laureate and a chemist at the University of Toronto.

But in a follow-up memo on 24 March, McDougall said "most 'researcher directed' and basic work is now carried out in academic institutions. Duplicating the efforts of universities at NRC doesn't make much sense."

Four proposed 'flagship programmes' described in the original memo, each with a marketable outcome, provide a glimpse at the direction the agency has in mind. They include developing a strain of wheat resilient to environmental stress; improving the manufacture of printable electronics; increasing domestic production of biocomposite materials; and using algae to soak up carbon dioxide emissions from industry. NRC researchers have expressed concern that jobs and programmes that do not fit with the new agenda are at risk. The agency declined to comment.

Tom Brzustowski, who studies commercialization of innovation at the University of Ottawa, says that the adjustment to the NRC's focus will support areas that have

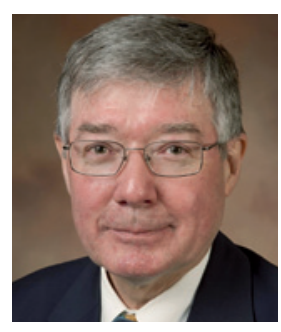

"Duplicating the efforts of universities at NRCdoesn't make much sense." John McDougall been weak. "By focusing on the flagship programmes there is stil room to do the whole spectrum of research. It's a good strategic move," he says.

But the news has rekindled anxiety over how Canada's government has been directing science funding - criticisms that have grown sharper as the federal election on 2 May approaches.

On 22 March, the government presented its 2011 budget, which offered modest increases to the federal research councils, but did not make up for cuts in 2009 (see Nature $457,646 ; 2009)$. The budget also included multimillion-dollar investments in neuroscience and physics. Few question the quality of work that such investments would produce, but critics say that the government is exerting too much control over the country's research, rather than allowing peer review to guide funding.

"It's risky to divert funds away from the granting councils, but the government does it because it looks politically better for them," says Robert Dunn, associate director of scientific affairs at the Montreal Neurological Institute. "Peer review is the very best mechanism to ensure that the limited research resources we have are allocated to the best researchers and projects." 